\title{
Metapoesia na Elegia 1.3 de Tibulo
}

Daniel Bueno de Melo Serrano

\begin{abstract}
Resumo: A obra elegíaca de Álbio Tibulo (55?-19? a.C.), poeta romano do chamado período angústeo, contém passagens que, por aludirem ao próprio fazer poético, podem ser classificadas como metapoéticas. Para investigar como se dá esse procedimento e quais são seus efeitos, este artigo se centra na terceira elegia do primeiro livro do autor e dispensa particular atenção à recorrência de termos polissêmicos que, segundo defendemos, podem ser lidos como referência ao gênero elegíaco e a outros gêneros poéticos. A análise é precedida por uma tradução integral em verso do poema.
\end{abstract}

Palavras-chave: Tibulo; elegia latina; intertextualidade; metapoesia.

\section{Texto da Elegia I, 3 de Tibulo}

Ibitis Aegaeas sine me, Messalla, per undas, o utinam memores, ipse cohorsque, mei!

Me tenet ignotis aegrum Phaeacia terris, abstineas auidas Mors modo nigra manus.

Abstineas, Mors atra, precor: non hic mihi mater quae legat in maestos ossa perusta sinus, non soror Assyrios cineri quae dedat odores et fleat effusis ante sepulcra comis;

Delia non usquam, quae me cum mitteret urbe dicitur ante omnes consuluisse deos.

Illa sacras pueri sortes ter sustulit: illi rettulit e trinis omina certa puer.

Cuncta dabant reditus, tamen est deterrita numquam quin fleret nostras respiceretque uias.

Ipse ego solator, cum iam mandata dedissem, 
quaerebam tardas anxius usque moras: aut ego sum causatus aues aut omina dira

Saturniue sacram me tenuisse diem.

O quotiens ingressus iter mihi tristia dixi offensum in porta signa dedisse pedem!

Audeat inuito ne quis discedere Amore aut sciat egressum se prohibente deo.

Quid tua nunc Isis mihi, Delia, quid mihi prosunt illa tua totiens aera repulsa manu, quidue, pie dum sacra colis, pureque lauari et (memini!) puro secubuisse toro?

Nunc, dea, nunc succurre mihi, nam posse mederi picta docet templis multa tabella tuis, ut mea uotiuas persoluens Delia noctes ante sacras lino tecta fores sedeat

bisque die resoluta comas tibi dicere laudes insignis turba debeat in Pharia.

At mihi contingat patrios celebrare Penates Reddereque antiquo menstrua tura Lari. Quam bene Saturno uiuebant rege, priusquam tellus in longas est patefacta uias! Nondum caeruleas pinus contempserat undas effusum uentis praebueratque sinum; nec uagus ignotis repetens compendia terris presserat externa nauita merce ratem.

Illo non ualidus subiit iuga tempore taurus, non domito frenos ore momordit equus; non domus ulla fores habuit, non fixus in agris qui regeret certis finibus arua lapis; ipsae mella dabant quercus, ultroque ferebant obuia securis ubera lactis oues; non acies non ira fuit non bella nec ensem immiti saeuus duxerat arte faber.

Nunc Ioue sub domino caedes et uulnera semper, nunc mare, nunc leti mille repente uiae. 
Parce, pater: timidum non me periuria terrent, non dicta in sanctos impia uerba deos.

Quod si fatales iam nunc expleuimus annos, fac lapis inscriptis stet super ossa notis:

HIC IACET IMMITI CONSVMPTVS MORTE TIBVLLVS,

Messallam TERra DVM SEQVITVRQVE MARI.

Sed me, quod facilis tenero sum semper Amori, ipsa Venus campos ducet in Elysios.

Hic choreae cantusque uigent, passimque uagantes

dulce sonant tenui gutture carmen aues;

fert casiam non culta seges totosque per agros

floret odoratis terra benigna rosis:

ac iuuenum series teneris immixta puellis

ludit et assidue proelia miscet Amor.

Illic est cuicumque rapax Mors uenit amanti,

et gerit insigni myrtea serta coma.

At scelerata iacet sedes in nocte profunda abdita, quam circum flumina nigra sonant,

Tisiphoneque impexa feros pro crinibus angues saeuit et huc illuc impia turba fugit;

tunc niger in porta serpentum Cerberus ore stridet et aeratas excubat ante fores.

Illic Iunonem temptare Ixionis ausi uersantur celeri noxia membra rota, porrectusque nouem Tityos per iugera terrae assiduas atro uiscere pascit aues.

Tantalus est illic et circum stagna sed acrem iam iam poturi deserit unda sitim;

et Danai proles, Veneris quod numina laesit, in caua Lethaeas dolia portat aquas.

Illic sit quicumque meos uiolauit amores, optauit lentas et mihi militias.

At tu casta, precor, maneas sanctique pudoris assideat custos sedula semper anus.

Haec tibi fabellas referat positaque lucerna 
deducat plena stamina longa colu,

ac circum, grauibus pensis affixa, puella

paulatim somno fessa remittat opus.

Tunc ueniam subito nec quisquam nuntiet ante

sed uidear caelo missus adesse tibi.

Tunc mihi qualis eris, longos turbata capillos,

obuia nudato, Delia, curre pede.

Hoc precor: hunc illum nobis Aurora nitentem

Luciferum roseis candida portet equis.

\title{
Tradução da Elegia I, 3 de Tibulo $^{1}$
}

\author{
Seguis sem mim, Messala, por egeias ${ }^{2}$ vagas, \\ quem dera todos vos lembreis de $\mathrm{mim}^{3}$ ! \\ Doente me detém em terra estranha a Feácia ${ }^{4}$;
}

1 Este artigo é parte de projeto de Iniciação Científica desenvolvido com apoio da Fundação de Amparo à Pesquisa do Estado de São Paulo (FAPESP), processo no 2012/15316-0. As opiniões, hipóteses e conclusões ou recomendações expressas neste material são de minha responsabilidade e não necessariamente refletem a visão da FAPESP. No artigo, todas as abreviaturas de obras latinas seguem o padrão da edição de 1968 do Oxford Latin Dictionary, doravante OLD.

2 Aegaeas: do Egeu, mar localizado entre a Grécia e a atual Turquia.

3 O utinam...mei: "quem dera lembrados, tu próprio e a comitiva, de mim". Para PUTNAM (1973, p. 76), a repetição dos pronomes de primeira pessoa - me (v. 1) e mei (v. 2) - estabeleceria, já sonoramente, a ligação entre o eu poético e o interlocutor, Messala (Messalla, v. 1). Quanto ao aspecto sonoro, o mesmo se poderia dizer de memores (v. 2). A exploração de fonemas nasais fica evidente também em siNe (v. 1), uNdas (v. 1) e utiNaM (v. 2). Com a despedida para um viajante, o poema retoma tópos da poesia antiga (propempticon) recorrente na época de Augusto, inclusive na elegia de Propércio (1.6 e 1.8) e Ovídio (Am. 2.11). Entre os elementos que caracterizam tais poemas de despedida, temos nesta elegia o verbo "ir" em segunda pessoa, indicando a partida do interlocutor (ibitis, v. 1), referência à travessia do mar, o pedido para ser lembrado e desculpas por não poder acompanhar o amigo na viagem; cf. referências a poemas desse tipo em MALTBY (2002, p. 184) e CAIRNS (2010, p. 167).

Cohors: na linguagem bélica, é o termo utilizado para designar uma subdivisão do exército (OLD, 3), embora possa significar, em sentido mais amplo, um efetivo ou equipe (acepção 2). Neste emprego por parte de Tibulo, o termo pode ser referência à comitiva que acompanha Messala, enquanto governante (OLD, 5; PUTNAM, p. 74).

4 Phaeacia: pode-se ver aqui não apenas uma referência geográfica, mas também uma alusão épica. Isso porque a visita de Odisseu à ilha habitada pelos Feácios, povo mítico governado pelo rei Alcínoo, é narrada na Odisseia (especialmente nos cantos 6 e 7) de Homero (cf. MALTBY, p. 183; Brill's New Pauly). A associação do local mítico com a ilha de Corcira, atualmente Corfu, encontra testemunho em Plínio, o Velho (Nat. 4.52), que afirma ser Corcira chamada, por Homero, de Feácia (Homero dicta...Phaeacia). Sua 
contém, ó negra Morte, as mãos vorazes. ${ }^{5}$

Contém, Morte atra, imploro: aqui não tenho mãe

que ao seio aflito colha o pó dos ossos ${ }^{6}$,

não tenho irmã que atire essência assíria ${ }^{7}$ às cinzas

e chore, a coma solta ${ }^{8}$, ante o sepulcro;

nem mesmo Délia; aquela que, ao me dispensar?,

já (dizem) consultara os deuses todos.

Três vezes tira a sacra sorte de um vidente:

das três lêt ${ }^{10}$ ele a ela augúrios certos.

Retorno davam todos: nada a demoveu

localização é discutida (cf. MALTBY, p. 186). Ao mencionar a ilha, o eu poético estaria, de acordo com LEE-STECUM (1998, p. 103), associando sua figura não apenas à de Odisseu (tendo deixado para trás, como este a Penélope, sua Délia), mas possivelmente à de Elpenor, companheiro abandonado por Ulisses na ilha de Circe, e que depois reaparece no mundo dos mortos. A última hipótese aproximaria a figura de Ulisses não à do eu poético, mas à de Messala, o que sublinharia a postura antibélica da persona elegíaca (cf. LEE-STECUM, p. 104). Essa distinção de papeis é observável já na elegia inaugural de Tibulo, quando, dirigindo-se a Messala, o eu poético afirma: "a ti convém guerrear" (te bellare decet, 1.1.53).

5 Modo: por motivos métricos, deixamos de traduzir modo ("um pouco", "por um instante"; cf. OLD, 1).

6 Ossaperusta: "ossos queimados". Aqui há referência ao ritual do ossilegium, que MALTBY (p. 187) assim descreve: "estando a pira extinta, os ossos eram molhados com vinho e leite, misturados com perfumes e especiarias e dipostos numa urna em uma sepultura".

7 Assyrios: de acordo com PUTNAM (p. 75), seria costume atirar essências aromáticas à pira funerária. Seria ainda frequente entre os poetas a confusão entre Assíria e Síria, esta última célebre pelos perfumes (cf. PUTNAM, p. 75; MALTBY, p. 188). O OLD registra o emprego do adjetivo Assyrius para referir fragrâncias, abonando, entre outros, Catulo (68.144) e Horácio (Carm. 2.11.16).

8 Effusis...comis: o desespero diante da morte é descrito em 1.1.67-68 - parce solutis crinibus ("poupa os soltos cabelos") - também com recurso à imagem dos cabelos (no caso, os de Délia). A expressão aparece ainda em Propércio (2.13.56) e Ovídio (Am. 1.9.38; Ars 3.784); cf. MALTBY (p. 188).

9 Me cum mitteret urbe: leia-se "ao deixar-me partir da cidade". O significado do verbo mittere, nessa passagem, é "deixar alguém seguir seu caminho" (OLD, 2). PUTNAM (p. 76) destaca ainda o emprego de urbe, no caso ablativo, desacompanhado da preposição $a b$, o que seria raro em latim clássico.

10 Sustullit...rettulit. neste momento em que o eu poético, em pensamento, se transporta a Roma, traduzimos aqui o perfeito por um presente histórico. Na encenação, PUTNAM (p. 76) identifica dupla troca de papeis: é Délia quem tira, ela mesma, a sorte, função que caberia a um assistente, identificado no poema como puer ("menino"); este, por sua vez, é alçado à posição de sortilegus, e transmite os presságios. O desarranjo sugere certa inquietação por parte de Délia, que parece apressar o ritual. Sobre a consulta quanto ao futuro como lugar-comum de um poema propempticon; cf. MALTBY (p. 188). Trinis: a tradição manuscrita registra e trinis ("de volta das encruzilhadas"), ao passo que e trinis é emenda proposta por Broukhusius (cf. MALTBY, p. 189) e adotada por MALTBY e PUTNAM. A proximidade de ter ("três vezes"), no verso anterior, dá força à hipótese, embora a opção por trimiis se legitime não apenas pela carga supersticiosa do vocábulo, como também por recorrer em 1.1.12 e 1.5.56. Nessas duas ocorrências, o termo ocupa posição análoga no pentâmetro. Certa: são muitos os significados possíveis para o adjetivo, que qualifica omina ("augúrios"). Em referência a sinais ou informações, pode transmitir a ideia de "certeza" (OLD, 5), "confiabilidade" (OLD, 7) e até de algo "inequívoco" (OLD, 9) ou "inevitável” (OLD 6). 
de me chorar e remoer as idas ${ }^{11}$.

Consolador e aflito, eu mesmo, as ordens dadas ${ }^{12}$,

em morosas delongas ${ }^{13}$ insistia:

culpei as aves pelo atraso, ou maus augúrios,

ou mesmo o de Saturno sacro dia ${ }^{14}$.

E quanto não julguei, partindo, desastroso

presságio haver topado o pé na porta!

Largar não se ouse, pois, Amor contrariado,

ou lembre que partiu vetando-o um deus.

De que me serve agora, Délia, a tua Ísis ${ }^{15}$,

de que os por tua mão vibrados bronzes ${ }^{16}$ ?

11 Nostras...uias: a expressão aparece em 1.1.52, igualmente acompanhada do verbo flere ("chorar"); cf. LEE-STECUM (p. 107). Nesta elegia, uia é retomada nos versos 36 e 50.

12 Cum iam mandata dedissem: a conjunção cum, quando acompanhada por verbo no subjuntivo, confere à oração adverbial matizes diversos: temporal, causal ou concessivo (cf. CART, 1986, p. 140). Somada a isso a vagueza de mandata, que em geral designa uma ordem ou instrução (cf. OLD), mas cujo destinatário neste caso é indefinido, resulta um dístico que se abre a muitas interpretações. PUTNAM (p. 76) interpreta mandata como "my (final) injunctions" ("minhas últimas determinações"), do que depreendemos tratar-se, conforme explicita MALTBY (p. 189), dos últimos preparativos antes da viagem (como em Catul. 64.214; Ov. Tr. 1.3.59; Ep. 15.105): ordens, portanto, não necessariamente destinadas a Délia. A tradução de MOSELLA (1938, p. 14) também assim interpreta o passo: "quando già avevo dato le ultime disposizioni per la partenza". Menos definitiva, a versão de PONCHONT (1955, p. 24) mantém a nuança temporal: "quand j'avais déjà donné mes ordres". MACRIS explora a matiz concessiva (1992, p. 37): "malgré mes ordres". FRAUSTADT (1940, p. 17), por fim, mantém a indefinição, embora defina claramente Délia como destinatária das palavras do eu poético: "Trost sprach ich selber ihr zu mit letzten scheidenden Worten". 13 Tardas...moras: interpreta-se o substantivo mora aqui como "algo que impede a ação imediata", "impedimento" (OLD, 8). O adjetivo que o qualifica, tardus, significa "lento" (OLD, 1, 2 e 3) ou até "tardio", "atrasado" (acepção 4). No caso, os obstáculos (moras) desejados não seriam propriamente "lentos" (tardas); representariam antes lentidão, atraso.

14 Saturniue...diem: de acordo com MALTBY (p. 190), trata-se, possivelmente, da primeira referência literária, em latim, ao sábado. Para explicar associação do sábado com a má sorte, o estudioso aventa algumas possibilidades, dentre as quais que "sendo a Idade de Ouro de Saturno caracterizada pela ausência de viagem, seria particularmente pouco propício dar início a uma jornada no dia dele" (p. 190). Para mais hipóteses, cf. MALTBY ad loc. Sobre o deus Saturno, cf. ainda nota ao verso 35.

15 Isis: o culto à deusa egípcia começa a ser difundido em Roma na época de Sula, embora tenha encontrado resistência de grupos conservadores; em 28 a.C., Augusto proibiria a construção de templos à deusa no perímetro da cidade (cf. KOENEN, 1976, p. 132), o que, no entanto, teria tido pouca influência sob as práticas; cf. MALTBY (p. 191), que destaca que as amadas retratadas nas elegias de Propércio e Ovídio também aparecem como devotas da divindade.

16 Aera: o uso metonímico de aes ("bronze") é atestado pelo OLD (acepção 6) e, neste caso específico, conforme apontam MOSELLA (p. 80), PONCHONT (p. 25), MACRIS (p. 39) e PUTNAM (p. 78), configuraria referência ao sistro, instrumento musical dotado de guizos utilizado no culto a Ísis (cf. OLD). 
De que lavar-te pura, pia honrando ${ }^{17}$ os ritos, e (lembro!) em leito puro, só, deitar-te ${ }^{18}$ ?

Agora corre, deusa, ajuda-me! (Que o podes ensinam de teu templo as muitas telas).

E a minha Délia, a te cumprir votivas noites ${ }^{19}$, se sente ${ }^{20}$ toda em linho às sacras portas,

e dos cabelos solta, insigne em turba fária ${ }^{21}$, se obrigue a duplas loas te tecer.

Louvar tão-só me caiba os paternais Penates, ao velho $\operatorname{Lar}^{22}$ repor mensais incensos.

Melhor viviam no reinado de Saturno ${ }^{23}$,

17 Colis: associado ao substantivo sacrum, o verbo colere pode designar o cumprimento de cerimônias religiosas (cf. Thesaurus Linguae Latinae 1688.7), em forma de culto. Doravante, para indicar o Thesaurus, usarei TLL.

18 Secubuisse: a acepção sexual do verbo cubare ("deitar-se") é atestada pelo OLD (acepção 2b); sua forma prefixada, secubare ("deitar-se sozinho"), sugere privação de companhia, sobretudo de um companheiro amoroso (OLD, 1b); daí também a acepção de "guardar castidade".

19 Votiuas persoluens Delia noctes: o verbo persoluere, quando ligado a notum, transmite a ideia de "retribuir a satisfação de um voto" (OLD, 2c). O adjetivo notiuus, por sua vez, caracteriza justamente aquilo que se oferece na retribuição da ordem. PUTNAM (p. 78) nota o inusitado de encontrarmos nos manuscritos uotiuas noces (em vez de nota, simplesmente, como acontece, por exemplo, em Prop. 2.26.49; cf. PICHON, 1991, p. 300). Na edição de MALTBY (p. 193), aqui adotada, temos uotiuas persoluens...noctes, adotando-se a conjuntura de Escalígero, que se baseia em Propércio (2.28.62, notiuas noctes, ei mibi, solue decem).

20 Ante...sedeat. cumprido o desejo, assumiria Délia a posição na qual, em regra, o próprio narrador elegíaco se coloca: fora das portas. Como contraste, cf. 1.1.56. Note-se, ainda, que sentar-se para súplicas (ut...sedeat, vv. 29-30) seria a postura típica do culto a Ísis, segundo MALTBY (p. 193).

21 Pharia: o adjetivo "fário" (Pharius) tem aqui o primeiro registro em língua latina. Relativo à ilha de Faros, próxima à Alexandria, pode ser empregado como sinédoque para o Egito (tal qual o nome da ilha; cf. OLD, 1), mas aqui faz referência ao culto da deusa Ísis Fária (cf. discussão em CAIRNS, 2010, pp. 64-65, e MALTBY, p. 193). Pharius ocorrerá também na elegia de Propércio (3.7.5) e Ovídio (Ars 3.635); cf. PUTNAM (p. 79). O fato de Délia se distinguir entre a multidão egípcia (i. e. de adoradores da deusa Ísis) pode fazer referência, de acordo com LEE-STECUM (p. 112), a sua suposta beleza ou devoção, ou ainda, simplesmente, a sua procedência romana.

22 Penates e Lari: associadas pelos romanos à proteção da casa, as duas divindades são frequentemente confundidas. CARDOSO (2004, p. 99) observa que o próprio Tibulo, ao evocar a figura de Eneias em 2.5.20, afirma que ele teria levado de Troia não os Penates (como faz Virgílio na Eneida), mas os Lares. De todo modo, o que os distingue é o fato de os Lares se relacionarem à proteção de toda a família (na concepção romana do termo, que inclui os escravos), ao passo que os Penates teriam ligação apenas com o pater familias (cf. Brill's New Pauly). Para o contraste no poema entre as divindades romanas, a que o eu poético se apega, e o culto de Ísis praticado por Délia, cf. MALTBY (p. 193).

23 Saturno: associado ao grego Cronos, o deus, segundo algumas versões, teria se estabelecido como rei do Lácio, vindo depois a ser destronado pelo filho Júpiter (cf. Brill's New Pauly). A associação entre a presença de Saturno no Lácio e a prosperidade do lugar é abordada, por exemplo, nos livros 7 e 8 da Eneida (cf. PUTNAM, p. 79). Em Tibulo, a menção ao deus reforça o ideal de uma Idade de Ouro perdida. 
antes de abrir-se a terra a longas idas!

Não desdenhara ainda o pinho ${ }^{24} \mathrm{o}$ azul das vagas, aos ventos não expusera o peito ${ }^{25}$ solto;

o navegante, atrás de lucro em terra estranha ${ }^{26}$, errando não pesara a nau ${ }^{27}$ de compras.

Robusto, então, não houve touro a dar-se aos jugos ${ }^{28}$, nem cavalo a morder, domado, as rédeas;

Não tinham porta as casas; com limites certos, não regia ${ }^{29}$ as lavouras uma pedra;

carvalhos davam mel, por conta própria o leite ${ }^{30}$

24 Pinus: o uso metonímico de pinus ("pinho") para significar uma embarcação é elevado, encontrando paralelo, entre outros, em Virgílio (Ecl. 4.38) e Ovídio (Met. 14.248), cf. OLD, 2. Semelhante figura de linguagem ocorre no verso 40 , em que ratis ("remo") designa não apenas o instrumento, mas toda a embarcação.

25 Sinum: o primeiro sentido de sinus é o de "prega", ou seja, uma concavidade formada pelo dobrar de um tecido (cf. ERNOUT \& MEILLET, 1967, p. 629). Daí passar a designar o peito, parte do corpo coberta por roupas plissadas (OLD, 2; Tib. 1.6.40). Em abstrato, o termo sugere a ideia de abrigo, refúgio (acepção 2 e 3) e é referido como sede das emoções e do pensamento (acepção 5). Neste emprego em contexto náutico, sinus indica o inchaço das velas de um navio, por ação do vento (acepção 7). No caso específico da poesia elegíaca, a acepção mais comum de sinus, de acordo com PICHON (p. 264), é "regaço", "colo" (gremium). Além das duas ocorrências nesta elegia, o termo recorre outras dez vezes apenas no livro I (1.1.31; 1.1.46; 1.2.98; 1.5.26; 1.6.18; 1.6.40; 1.8.30; 1.8.36; 1.9.70; 1.10.68). É significativo notar, por fim, que sinus é a última palavra do poema 1.10, servindo, portanto, como fecho para o primeiro livro.

26 Ignotis...terris: a expressão é a mesma do verso 3 e ocorre, como observa PUTNAM (p. 80), na mesma posição métrica. Também undas (v. 37) ecoa o início do poema (v. 1).

27 Ratem: sobre ratis ("remo") como metonímia para "nau", cf. nota ao verso 37. Cf. também 1.9.10 e MALTBY (p. 197).

28 Inga: embora ingum designe a peça que une o arado aos animais que o puxam, o termo é associado também à dominação amorosa (cf. PICHON, p. 177), do que temos exemplo em 1.4.16. Em associação a boues ("bois"), o termo aparece em 1.1.46. São as únicas ocorrências no livro I. No segundo, o termo aparece em 2.1.7 e 2.3.48.

29 Regeret: o mais comum seria esperar fines ("limites", "fronteiras") como complemento do verbo regere ("reger", "delimitar"); cf. PUTNAM (p. 80). Com efeito, encontramos exemplo da fórmula legal regere fines, por exemplo, em Cícero (Top. 23 e 46, cf. OLD, 1; Leg. 1.21.55 e MALTBY, p. 197). Aqui, no entanto, finibus aparece no caso ablativo, com ideia instrumental (cf. CART, p. 126), e o complemento do verbo é arua ("lavouras").

30 Obuia: qualificando ubera ("mamas"), o adjetivo obuius parece guardar aqui o significado primeiro de "estar a caminho", caracterizando algo "posicionado de modo a encontrar" outra coisa (OLD, 1). No caso, seriam as ovelhas (oues, v. 46) a levar (ferebant, v. 45) as mamas com leite (ubera lactis, v. 46) ao encontro dos homens, qualificados como "despreocupados", "seguros" (securis, v. 46). A ênfase (também marcada pelo advérbio ultro, v. 45) recai sobre o fato de serem os animais a fazê-lo espontaneamente, tal qual o fariam as plantas, como os carvalhos dando mel sem a intervenção de abelhas (segundo se infere de ipsae...quercus, v. 45; cf. MALTBY, p. 198): ou seja, toda a natureza estaria em harmonia com os humanos, que, nesse 
chegavam as ovelhas aos tranquilos;

A ira, o gume ${ }^{31}$, as guerras: nada. Com arte crua, não forjara o ferreiro rude ${ }^{32}$ a espada.

Sob Júpiter ${ }^{33}$, só mar e dor e sangue agora;

mil idas ${ }^{34}$, de repente, para a morte.

Poupa-me, ó Pai: não são perjúrios que me aterram, impiedades contra os deuses santos ${ }^{35}$.

Mas se a fatal idade agora já completo, faz nota sobre a ossada erguer-se lápide:

Aqui Tibulo Jaz, POR CRUA ${ }^{36}$ MORTE Gasto,

QUANDO A Messala EM TERra E MAR SEgUia. ${ }^{37}$

A mim, pois dócil sempre fui ao tenro Amor,

passado mítico, não a teriam ainda submetido a seu jugo. Nessa espécie de boa vontade ("willingness") que a natureza demonstra para com o homem, LEE-STECUM (p. 116) enxerga possível paralelo com a relação entre o eu poético e Délia: o elogio à espontaneidade e boa disposição da natureza poderia ser lido como exortação a que Délia correspondesse aos desejos dele. Grande parte dos motivos aqui associados à Idade de Ouro figura também na quarta Bucólica de Virgílio, em contexto semelhantemente idealizado: lá estão os animais que, espontaneamente, oferecem leite (vv. 21-22); o carvalho como fornecedor de mel (v. 30); a navegação comercial (vv. 38-39); o uso dos animais para a agricultura (v. 41).

31 Acies: significando a princípio "gume", "ponta" (OLD, 1), o termo pode também designar uma "batalha", conforme indica o TLL (409.53) ser o caso deste emprego por Tibulo. De todo modo, ambos os significados são reforçados, logo a seguir, por bella ("guerras") e ensem ("espada").

32 Saemus: epíteto de Juno na Eneida, guarda significados associados à ferocidade (OLD acepção 1), à violência (acepção 5) e à selvageria (acepção 3 e 4). Este último parece-nos mais adequado, dado o termo caracterizar, no poema, o artesão (faber). Já immiti, que qualifica arte, tem significado muito próximo e sugere a ideia moderna de "impiedade".

Duxerat: o verbo ducere aparece aqui significando "afiar", isto é, moldar um objeto pontiagudo (OLD, 23c).

33 Ioue: ver nota ao verso 35.

34 Viae: diferentemente das outras duas ocorrências do termo no poema (vv. 14 e 36), em que o significado mais apropriado era "viagem", uia, aqui, parece referência à multiplicidade de maneiras pelas quais a morte ameaça o eu poético (OLD acepção 8b).

35 In sanctos impia nerba deos: neste verso 52, a disposição dos termos em forma de quiasmo privilegia a antítese entre os adjetivos sanctos ("santos"), caracterizando os deuses (deos), e impia ("ímpios"), caracterizando as palavras (uerba); cf. MALTBY (p. 200).

36 Immiti: o adjetivo é o mesmo utilizado para qualificar a arte posta em prática a fim de se forjar uma espada (v. 48). Aqui, no entanto, a associação com a morte realça outro matiz semântico do termo: a designação do estado não maduro de um fruto, por exemplo. Daí podermos pensar em immitis, neste caso, como "prematuro" (cf. TLL 467.22 e MALTBY, p. 201).

37 Com origem na poesia helenística, o emprego de epitáfio em poesia é frequente na poesia da época de Augusto (por exemplo, em Verg. Ecl. 5.42.4), sendo este o primeiro exemplo em elegia de que se tem notícia (MALTBY, p. 201). Cf. ainda epitáfios em Propércio (2.13.35-6; 4.7.85-6) e Ovídio (Am. 2.6.61-2; $\operatorname{Tr}$ 3.3.73-6). 
me guia a própria Vênus aos Elísios ${ }^{38}$.

Ali viceja o canto e a dança, e doce cântico

vagando as aves soam, tênue a glote;

dá cinamomo ${ }^{39}$ o solo inculto e, pelos campos,

o olor das rosas cobre a boa terra.

Alas de jovens brincam junto a tenras moças,

e Amor assiduamente adere ${ }^{40}$ às lutas.

Está por lá o que, amando, a Morte arrebatou ${ }^{41}$,

trançada murta ${ }^{42}$ leva em coma insigne.

À parte jaz, na noite funda, o celerado

setor $^{43}$, com negros rios soando à volta;

despenteada das ferozes cobras, ira-se

Tisífone $^{44}$, e dispersa a turba impia;

38 Elysios: por oposição ao Tártaro, os Campos Elísios, região do mundo dos mortos reservada aos justos e aos heróis (cf. Brill's New Pauly), serão aqui o lugar dos que se portaram bem em relação ao amor. $\mathrm{Na}$ elegia, a origem da associação com a Idade de Ouro tem sido objeto de discussão, mas, de toda forma, tende-se a apontar como tibuliana a caracterização dos Campos Elísios como lugar para amantes, sem dúvida com referências a outras representações do mundo dos mortos na poesia antiga. Para discussão e simularidades, cf. MALTBY (p. 202), que, além de aventar fontes gregas, aponta paralelos em Virgílio (A. 6.440-76) e Propércio (4.7.59-69).

39 Casiam: o OLD registra casia como "uma árvore, provavelmente uma espécie do gênero Cinnamomum". Por extensão, a palavra designaria também os produtos de uso perfumante ou medicinal provenientes da planta; cf. também Verg. G. 2.466; TLL 515.62.

40 Miscet: o verbo miscere é o mesmo que aparece no verso anterior, prefixado e na forma do particípio immixta. Significa "misturar", "juntar", inclusive para união sexual, "unir" (OLD, 4c). Quando acompanhado de um substantivo como proelium ("combate"), é expressão de teor militar (cf. MALTBY, p. 204), que transmite a ideia de "aderir" a uma disputa (OLD, 13b).

41 Rapax Mors: "a Morte rapaz", "arrebatadora".

42 Myrtea: relativo a myrtus, árvore de pequeno porte consagrada a Vênus (cf. PUTNAM, p. 83) que em português se diz "murta" ou "mirto" (cf. Houaiss). A passagem lembra a descrição dos Campos Lugentes na Eneida de Virgílio, descrito como o lugar dos que morreram por amor e foram circundados por floresta de mirto (myrtea...silua, A. 6.443); cf. MALTBY (p. 204).

43 Scelerata...sedes: para este emprego por Tibulo, o OLD (sedes, acepção $1 \mathrm{f}$ ) indica a seguinte definição: "the place of torment in the underworld". PUTNAM (p. 84) afirma tratar-se do local de repouso daqueles que cometeram scelera ("crimes"). O emprego de sedes, portanto, tem significado mais amplo que o restrito "assento"; cf. também Ov. Met. 4.456.

44 Tisiphone: conhecida por ser a vingadora dos assassinatos, Tisífone é uma das Fúrias, ao lado de Megera e Alecto. De acordo com a versão oferecida pela Eneida (6.572), é Tisífone que, na posição de guardiã do Tártaro a mando de Radamanto (juiz dos infernos), se responsabiliza pelas torturas (cf. Brill's New Pauly). Impexa feros pro crinibus angues: PUTNAM (p. 84) interpreta feros angues ("ferozes cobras") como acusativo de relação (cf. CART, p. 123) associado a impexa ("despenteada"). Assim, teríamos, literalmente: "despenteada quanto às ferozes cobras no lugar de cabelos (pro crinibus)". MALTBY (p. 205) chama atenção para a sonoridade do verso latino, com aliterações em $/ \mathrm{s} / \mathrm{e} / \mathrm{ks} /$, imitando o sibilar das cobras. 
à porta o negro Cérbero ${ }^{45}$, serpente à boca,

vigia e late ante as portadas brônzeas.

Lá, de Ixião, que ousara a Juno assediar ${ }^{46}$, culpado gira o corpo em ágil roda;

por nove jeiras estendido, Tício ${ }^{47}$ as atras

tripas dá de comer a assíduas aves.

Eis Tântalo ${ }^{48}$, água à volta; quase já sacia

a intensa sede - e foge-lhe a maré.

E trazem as Danaides ${ }^{49}$, que ofenderam Vênus, leteias $^{50}$ águas em vazados potes.

45 Cerberus: embora a imagem de um cão feroz a guardar as entradas do mundo dos mortos remonte a Homero, a primeira menção a Cérbero na literatura grega antiga ocorre em Hesíodo (Theog. 306-312); cf. Brill's New Pauly. A partir daí, as versões são unânimes em conferir-lhe aspecto aterrorizante e, por muito que haja divergências, costuma-se dotá-lo de várias cabeças: cinquenta em Hesíodo, cem em Píndaro (fr. 162), mas normalmente três; cf. Verg. A. 6.419; Ov. Met. 10.21; MALTBY (p. 208). O monstro será novamente mencionado na última elegia do primeiro livro de Tibulo (1.10.36).

46 Temptare: o verbo sugere aqui uma investida sexual ("to make a sexual assault", OLD, 9b). Ixionis: depois de assassinar um parente e ser purificado pelo próprio Júpiter, Ixião (rei mítico dos lápitas) teria tentado seduzir a esposa do deus, Juno. Como punição, giraria eternamente preso a uma roda (cf. Brill's New Pauly). Virgílio faz menção a esse castigo - do qual o primeiro testemunho seria o de Píndaro (cf. PUTNAM, p. 84) - nas Geórgicas (3.38 e 4.484). Já na Eneida (6.601), o castigo de Ixião aparece assimilado ao de Pirítoo: o de carregar, também sem cessar, uma pedra que lhes cai sobre a cabeça.

47 Tityos: depois de assediar Latona, o gigante Tício, filho de Júpiter com a Terra, é morto por Apolo e Diana e, no mundo dos mortos, tem as vísceras bicadas por pássaros (cf. Brill's New Pauly). Virgílio (A. 6.597) emprega o mesmo verbo porrigo ("estender") - aqui na forma participial porrectus - para se referir às dimensões agigantadas de Tício.

48 Tantalus: varia de versão para versão o crime pelo qual Tântalo, filho de Júpiter, é punido (cf. Brill's New Pauly). Para com os deuses terá sido sua falta, pesando-lhe ora ter roubado aos deuses o alimento (néctar e ambrosia), ora ter revelado seus segredos. Uma vez que, nos demais mitos referidos no poema, fica evidente que se trata de condenação por amor, MALTBY (p. 208) assume haver ali uma referência erudita a episódio mitológico que caracterizaria assim o caso de Tântalo. De todo modo, Tibulo incorpora apenas uma parte de sua punição: a água (stagna) que lhe foge (deserit) sempre que a vai beber (poturi); cf. Verg. A. 6.602-603. Além disso, penderiam sobre sua cabeça os frutos de uma árvore, que o vento afastaria sempre que Tântalo os tentasse apanhar.

49 Danai proles: na mitologia, as cinquenta filhas de Dânao eram ditas Danaides. Elas teriam sido pretendidas pelos cinquenta filhos de Egito, irmão gêmeo com quem Dânao rompera relações. Assim, o pai recomenda às filhas que simulem aceitar o pedido, para então assassiná-los na noite do casamento. A única a descumprir o plano foi Hipermnestra. Seria seu marido, Linceu, a vingar os irmãos. Como punição, coube às Danaides, no mundo dos mortos, preparar o próprio banho contando apenas com recipientes cravados de buracos, por onde a água escorria (cf. Brill's New Pauly).

50 Lethaeas: na hidrografia do mundo dos mortos, o Letes é o rio associado ao esquecimento. Cana: embora em geral transmita a ideia de concavidade, o adjetivo cauns designa aqui recipientes (dolia) porosos, isto é, dotados de numerosos orifícios (OLD, 4b). 
Esteja lá o que os meus amores profanou ${ }^{51}$, quis minhas as campanhas prolongadas ${ }^{52}$.

Mas tu, sê casta: o teu pudor o guarde santo, sentada, uma senhora diligente ${ }^{53}$.

Que ela te conte histórias; posta a lamparina ${ }^{54}$, do fuso cheio puxe $e^{55}$ longos fios.

E a moça, ao lado, entregue à tarefa pesada, aos poucos, sonolenta, deixe a lida.

Então virei de pronto, anúncio não se faça, do céu tão-só me vejam vindo a ti.

Então - não importa se desfeita a cabeleira a mim, com pés desnudos, Délia, corre.

Isto eu imploro: traga-nos a Aurora, cândida, o amanhecer com seus cavalos róseos ${ }^{56}$.

51 Violanit: o significado primeiro de violare guarda fundo religioso, embora tenha também matiz sexual (OLD, 2c). Deste último emprego, temos exemplo tibuliano em 1.6.51; cf. também 1.2.81, 1.2.27-8. Sobre o caráter sagrado do amor em Tibulo, cf. MALTBY (p. 209).

52 Lentas: a campanha do eu poético, militar ou amorosa, é lenta, isto é, demora a passar, prolonga-se (OLD, 5). A palavra militia, embora evoque aqui a expedição militar durante a qual o eu poético cai doente, é empregada com frequência como metáfora militar para o amor (como indica o nome do tópos elegíaco da militia amoris), indicando aqui os esforços (labores) e preocupações (curae) a que se sujeita um amante (cf. PICHON, p. 201).

53 Assideat... anus: uma reminiscência de cena de comédia nova (Ter. Hau. 275-307 e, infere-se, o modelo menândrico) é sugerida por MALTBY a essa passagem (p. 210), que também lembra, como o próprio estudioso aponta, a situação de Penélope, tecendo à espera do marido na épica homérica (Od. 2.93-109). Para referência humorística da personagem de Penélope na comédia nova, cf. Plauto, Estico, v. 1 sq., cf. CARDOSO, 2006, ad loc.

54 Lucerna: lamparina a óleo ou, por extensão, a vigília de um escritor por motivo de estudo ou trabalho (cf. OLD). Na tradução, MACRIS (p. 43) tende para esta última acepção e verte posita lucerna por "durant la veillée". Preferem o significado mais concreto PONCHONT ("près de la lampe", p. 27), MOSELLA ("al chiaror di una lucerna", p. 18) e FRAUSTADT ("beim traulichen Scheine der Lampe", p. 23).

55 Deducat: o verbo deducere ("levar para baixo") aqui significa só "puxar" o fio ("draw out", "spin"; cf. OLD, 4), aplicado à tecelagem - que era, como lembra MALTBY (p. 210), "atividade par excellence da casta matrona".

56 Hunc illum nobis Aurora nitentem/ Luciferum roseis candida portet equis: "que a Aurora, cândida, nos traga Lúcifer (composto de lux + ferre, "aquele que traz a luz") reluzente nos cavalos róseos". No texto latino, referências a brilho e nitidez são enfáticas. MALTBY (p. 213) vê referências metapoéticas nos adjetivos nitens (referência a estilo elegante, polido) e candidus (designando quer o poeta, cf. Hor. Ep. 1.4.1, quer seu estilo "puro"). Luciferum: personificação masculina da estrela da manhã (o planeta denominado Vênus); na mitologia, Lúcifer era considerado filho da Aurora (cf. OLD). A referência aos cavalos cor-de-rosa (roseis... equis, v. 94) tem certamente nuanças épicas, remetendo a Verg. A. 6.535; 7.26, e, como aventa MALTBY (p. 214), à homérica "Aurora dos dedos cor-de-rosa" (epíteto tão frequente) e seus cavalos (Od. 23.244-6). 
A elegia tem início com o narrador deslocado. Doente, ele se vê impedido de continuar a expedição que o levara para longe de casa. No território Feácio, sozinho e debilitado, ele roga à Morte, personificada e sombria, que contenha a avidez de suas mãos (auidas...manus, v. 4) e o mantenha vivo. Afinal, se morresse ali, não teria quem lhe cumprisse os ritos funéreos: nem mãe (mater, v. 5), nem irmã (soror, v. 7), nem amada (Delia, v. 9). A gradação reserva um dístico para cada figura feminina e culmina na evocação de Délia, puella a quem o eu poético tibuliano também em outros poemas dirige seus lamentos. Já tem início aí o segundo movimento da elegia. O narrador recua no tempo para mostrar como foi - ou imaginar como teria sido - sua despedida da amada, que o dispensara da cidade (mitteret urbe, v. 9). Se nos fiarmos no que relata o eu poético, notaremos que Délia reluta em abandoná-lo: ela consulta os deuses (v. 10) antes de deixá-lo partir, e chega mesmo a recorrer a um vidente, que lhe assegura o retorno do companheiro ${ }^{57}$ (vv. 9-14):

Delia non usquam, quae me cum mitteret urbe dicitur ante omnes consuluisse deos.

Illa sacras pueri sortes ter sustulit: illi rettulit e trinis omina certa puer.

Cuncta dabant reditus, tamen est deterrita numquam quin fleret nostras respiceretque uias.

Nem mesmo Délia; aquela que, ao me dispensar, já (dizem) consultara os deuses todos.

Três vezes tira a sacra sorte de um vidente: das três lê ele a ela augúrios certos.

Retorno davam todos: nada a demoveu de me chorar e remoer as idas.

O irônico da passagem reside no fato de que é no mínimo duvidosa a versão do narrador. Que Délia tenha consultado os deuses (v. 10) e, mais tarde, chorado a partida do companheiro (v. 14) são fatos incertos, talvez meras suposições do narrador, que parece crer excessivamente na amada. O que relata, afinal, é informação ouvida de terceiros, proveniente de fonte não identificada (dicitur,

57 De acordo com PUTNAM (p. 76), o costume era que a sorte fosse tirada por um assistente e interpretada pelo sortilegus. No caso, é a própria Délia quem assume a parte inicial do processo, relegando ao puer a interpretação. E repete três vezes o ato, de acordo com MALTBY (p. 188), não apenas pela superstição que o número representa (cf. 1.2.56), mas também como confirmação do presságio favorável. 
"conta-se" "58, v. 10). Estaríamos, assim, diante de uma situação ambígua. Quando Délia dispensa o companheiro e as sortes the asseguram seu retorno, ela chora (v. 14). O narrador, imediatamente, imputa o choro à partida. No entanto, se o choro se dá diante de presságios positivos, não será descabido ao leitor supor que Délia chore, afinal, porque a partida não é definitiva, isto é, porque não consegue se livrar definitivamente do companheiro. Este, por sua vez, parece cego a ponto de não enxergar senão boas intenções nas ações da amada. À parte isso, nota-se que o verso 14, reproduzido acima, evoca, por semelhanças temáticas, vocabulares e formais, uma passagem da elegia 1.1. No poema inaugural, a certa altura, afirmado já o ideal de rusticidade e pobreza, o narrador ratifica (1.1.51-52):

O quantum est auri pereat potiusque smaragdi quam fleat ob nostras ulla puella uias!

Oh, melhor perder-se quanto há de ouro e de esmeralda que chorar por nossas viagens alguma moça!

Vejamos como é eloquente a aproximação:

1.1.52: quam fleat ob nostras | ulla puella uias

1.3.14: $\quad$ quin fleret nostras | respiceretque uias

Pode-se destacar, em primeiro lugar, o emprego do sintagma nostras uias. Nas duas ocorrências, o pronome possessivo e o substantivo - separados como a sugerir o próprio distanciamento decorrente da viagem - ocupam posições equivalentes no pentâmetro: o primeiro logo antes da cesura, o outro no fim do verso. Nos dois casos, ainda, é flere ("chorar") o verbo que se emprega, em tempo do subjuntivo, ora presente, ora imperfeito. Em 1.1, o declarado desprezo pela riqueza, por parte do narrador, acentuava-lhe a parcimônia, análoga à do poeta elegíaco. O paralelo permite-nos avaliar o quanto de alegórico - e metapoético não teria também esta peça tibuliana.

Antes de tudo, é preciso notar que o poema 1.3 tem início com um quadro, por assim dizer, pouco elegíaco: contra o ideal que pregara nos poemas anteriores,

58 LEE-STECUM (p. 107) vê no emprego do verbo uma evidência de que o narrador não está, ele próprio, convencido das ações que Délia teria levado a cabo. Ao relatá-las, portanto, seria como se tentasse convencer também a si próprio da fidelidade da companheira. 
o narrador está em campanha militar. De fato, ao fazê-lo, Tibulo arrisca mesmo escapar aos limites do próprio gênero elegíaco ${ }^{59}$. Daí que toda a hesitação do narrador antes da partida, descrita entre os versos 15 e 22, possa ser interpretada como uma espécie de justificativa para a inclusão do tema, a princípio não adequado, porque exterior aos limites da elegia ${ }^{60}$. O narrador reluta em partir: protela a viagem (quarebam tardas...moras, v. 16), arranja desculpas (vv. 17-18) e chega a enxergar maus presságios (tristia...signa, vv. 19-20) nos eventos que a precedem. No fim do segmento um dístico resume, em entoação professoral, aquele que teria sido o pecado maior do narrador (vv. 21-22):

audeat inuito ne quis discedere Amore aut sciat egressum se prohibente deo.

Largar não se ouse, pois, Amor contrariado, ou lembre que partiu vetando-o um deus.

O amor - eis a lição - não deve ser contrariado e, se alguém ousar fazê-lo, deve estar ciente das consequências. O estado de debilidade em que se encontra o narrador no início do poema pode ser visto como um caso exemplar de desrespeito aos desígnios do amor. E é a esse infeliz presente que voltamos após o verso 22. Depois de rememorar as circunstâncias da partida, o eu poético volta a dirigir a palavra a Délia. Menciona a devoção da amada à deusa egípcia Ísis e, embora ele próprio mostre dúvidas em relação aos poderes da divindade (quid mibi prosunt, v. 23), chega a pedir-lhe ajuda de modo enfático (nunc, dea, nunc succurre mibi, v. 27). Em seguida, mesmo que o desespero lhe inspire crenças menos ortodoxas ${ }^{61}$, reafirma sua devoção pelos romanos Penates (v. 33) e Lares (v. 34). É essa, afirma, a crença que lhe cabe (contingat, v. 33).

Mas, afinal, o que caracteriza a infelicidade com a qual o narrador se afirma confrontado? A descrição da infelicidade o eu poético não a faz de maneira direta.

59 Assim, malgrado a aparente confusão entre as figuras do poeta e do eu poético, é interessante a consideração de Paul VEYNE (1985, p. 64) a respeito da passagem: "Presumindo-se que todo poeta vive como canta, um poeta elegíaco só deve viver para o amor, já que a elegia tem o amor como tema; seguindo seu protetor à guerra, Tibulo fez mais do que desobedecer ao Amor, seu verdadeiro deus: faltou para com a lei do gênero e para com sua definição de poeta".

$60 \mathrm{Na}$ recusa do eu poético a aventurar-se em outro gênero, sugerimos que se possa ver uma instância de recusatio. Sobre a incorporação de características do gênero épico na recusatio horaciana à épica, cf. DAVIS (1991).

61 Os mais conservadores veriam com resistência, à época do autor, o culto à divindade egípcia. Sobre a influência da cultura egípcia em Tibulo, cf. KOENEN (1976) e MALTBY (p. 191). 
Descreve, isso sim, uma Idade de Ouro idealizada, contra a qual seu estado momentâneo se ergueria como imagem em negativo: tudo o que de pior experimenta não teria existido nesse tempo mítico, cujas maravilhas se teriam perdido com a degradação da sociedade. O tempo da narração, assim, é marcado pela perda do bem e prevalência do mal. E é interessante notar como algumas imagens iniciais da elegia, à medida que são retomadas neste ponto, sublinham a infelicidade do narrador. $\mathrm{O}$ eu poético caíra doente em terras estranhas (ignotis...terris ${ }^{62}$, v. 3) enquanto navegava (per undas, v. 1) acompanhando o patrono Messala. Pois a Idade de Ouro seria marcada, entre outras coisas, pela inexistência da navegação (undas, v. 37), o que anularia a possibilidade de o navegante ver-se em terras estranhas (ignotis...terris, v. 39). Diferentemente da situação presente, o reinado de Saturno não seria o tempo das longas jornadas (longas...uiass ${ }^{63}$, v. 36).

Se no início associamos as viagens (uiae) ao ideal de vida - e de poesia - a que o poeta elegíaco pretende se opor, veremos agora assumirem significação mais ampla essas "terras estranhas" (terrae ignotae) em que o narrador se sente desconfortável. A imagem do navegante (na forma arcaica não sincopada nauita, v. 40, cf. Maltby ad loc.) a vagar (uagus, v. 39) por paragens incertas replica, de certa maneira, a própria posição do poeta elegíaco ao forçar os limites do gênero que pratica. Vejamos aspectos do poema que nos levam a essa interpretação. Em primeiro lugar, podemos recordar associações entre a épica e o próprio motivo da viagem $^{64}$. Além disso, no poema, o navegante arrisca-se em busca de recompensas (repetens compendia ${ }^{65}$, v. 39), um pouco como se mostra nesse poema o poeta elegíaco, de resto entusiasta da parcimônia. Diferentemente do que afirma no priamel da primeira elegia, em que atribui a outros as aspirações financeiras, aqui o poeta se apresenta como alguém que se aventurara à procura da elocução mais elevada que elegia não lhe permitiria alcançar; e, fazendo-o, assume em seguida uma postura algo autopunitiva, por exemplo exaltando o tempo - a Idade de Ouro - em que as pessoas e as coisas, menos dadas a arroubos, reconheciam e respeitavam sua

62 Mais uma vez nota-se como são calculadas as recorrências vocabulares. Nas duas passagens em que se emprega a expressão ignotis terris (versos 3 e 39), o sintagma ocupa posição equivalente no verso. O mesmo ocorre com o termo undas, no fim dos versos 1 e 37, precedido nas duas ocasiões de adjetivo (Aegaeas, v. 1; caeruleas, v. 37).

63 A Idade de Ouro é tema particularmente caro aos poetas do tempo de Augusto e caracteriza, em Tibulo, um período de superioridade moral da sociedade. MALTBY (p. 194) aponta que o tema remonta a Hesíodo e, em latim, a Lucrécio (5.925); cf. também Hor. Epod. 16; Ov. Am. 3.8.35; Met. 1.89.

64 Veja-se, por exemplo, no segundo livro das Geórgicas de Virgílio (vv. 40-45): o decus, o famae merito pars maxima nostrae, / Maecenas, pelagoque uolans da uela patenti. / Non ego cuncta meis amplecti uersibus opto, / non, mibi si linguae centum sint oraque centum, / ferrea uox. Ades et primi lege litoris oram; / in manibus terrae. non bic te carmine ficto / atque per ambages et longa exorsa tenebo.

65 Note-se em compendia o vocabulário legal, estranho à poesia da época de Tibulo; cf. MALTBY ad loc. 
posição no mundo. No entanto, é importante observar que a aparente autocrítica resulta em efeito poético, reforçando, mais uma vez, a forjada modéstia que caracteriza a elegia. A longa descrição do passado mítico da Idade de Ouro (vv. 35-48) culmina, por fim, no confronto com a realidade do narrador, marcada pela violência e pelos perigos (vv. 49-50):

nunc Ioue sub domino caedes et uulnera semper, nunc mare, nunc leti mille repente uiae.

Sob Júpiter, só mar e dor e sangue agora; mil idas, de repente, para a morte.

Diante desse quadro, resta ao eu poético pedir enfaticamente (nunc...nunc... nunc, vv. 49-50) a Júpiter que o poupe (parce, v. 51) - pedido semelhante ao que, em poemas anteriores, dirige a Délia (1.1.67-68) e Vênus (1.2.99). No caso, argumenta o narrador que o Pai (pater, v. 51) deveria poupá-lo porque jamais teria dirigido impiedades aos deuses (impia nerba, v. 52). E, no entanto, diz, aceitaria de bom grado caso lhe coubesse a morte (vv. 53-54). Chega mesmo a imaginar a inscrição que lhe poderia servir de epitáfio ${ }^{66}$, para em seguida afirmar (vv. 57-58):

sed me, quod facilis tenero sum semper Amori, ipsa Venus campos ducet in Elysios.

A mim, pois dócil sempre fui ao tenro Amor, me guia a própria Vênus aos Elísios.

No início da elegia, a partida do narrador levava a crer que teria agido contra a vontade de Amor (inuito...Amore, v. 21), e é mesmo provável que assim tenha procedido, já que partira em campanha militar; neste ponto mais avançado do poema, contudo, o narrador parece ocultar sua falta, de modo a garantir a simpatia

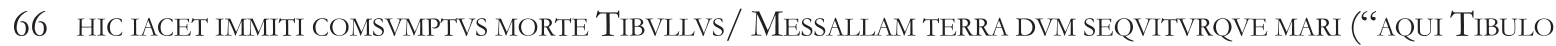
jaz, POR CRUa morte gasto,/ Quando a Messala em terra e mar Seguia”). LEE-STECUM (p. 118) vê com surpresa o fato de que o narrador prefira ser reconhecido pela campanha militar incompleta do que por sua devoção amorosa a Délia. De acordo com o estudioso, a escolha abriria muitas possibilidades de interpretação, dentre elas a de que a passagem realçaria a culpa de Messala pela morte do eu poético, já que isso não teria acontecido caso não o tivesse seguido. Sobre epitáfios na épica antiga, cf. DINTER (2005). 
dos deuses e, consequentemente, um melhor lugar no mundo dos mortos. Com alguma dissimulação, afirma sua constância (semper, v. 57) aos desígnios de Amor e confirma a crença na intervenção de Vênus ${ }^{67}$.

Notoriamente, nessa elegia, a imagem dos Campos Elísios, bem como do Tártaro, apresenta muitas similaridades com a retratada no livro VI da Eneida, de Virgílio: monstros como Cérbero, além dos condenados, aludem à paisagem virgiliana. Mas fazem-no, como já se reconheceu, caracterizando os inferi como mundo dos amantes, recompensados ou castigados pela conduta relativa ao amor. Observemos que outros aspectos, além desse, contribuem para que se associem os inferi especificamente ao amor elegíaco.

O dístico acima reproduzido apresenta dois adjetivos que retomam passagens da elegia 1.1. Naquele poema, o eu poético, afirmando-se rusticus (v. 8), manifesta o desejo de poder cuidar de suas tenras videiras (teneras...uites, v. 7) com mão hábil (facili...manu, v. 8) - o que, acreditamos, poderia ser lido como declaração de estilo, da elocução, por parte do narrador. Ora, o paralelo com a elegia inaugural torna muito significativo o dístico ora em apreço. A delicadeza do eu poético deixa de passar pelo "filtro" da agricultura para ser afirmada de maneira direta. Por muito que se tenha arriscado em terrenos não elegíacos, jamais teria posto de lado por completo a fidelidade ao amor - é isso, aparentemente, o que afirma o narrador. E é por isso mesmo que, caso venha a morrer, se mostra confiante de que Vênus - deusa do amor e, por extensão, da elegia - intervenha a seu favor.

A descrição dos Campos Elísios, aliás, é marcada por suprema delicadeza. Os pássaros cantam com doçura (dulce...carmen, v. 60) e timbre tênue (tenui ${ }^{68}$, v. 60); o campo é fértil mesmo que não cultivado (non culta seges, v. 61); e, se alguma batalha (proelia, v. 64) permite o Amor, é a das brincadeiras entre garotos e garotas - estas últimas, delicadas (teneris...puellis, v. 63). O poeta elegíaco parece projetar seu ideal ora no passado, pela lamentação de uma Idade de Ouro perdida, ora no futuro, pela esperança num pós-vida de sonho. A vida após a morte, por sua vez, apresenta-se dividida em duas vertentes opostas e, aparentemente, determinadas pelas ações levadas a cabo em vida. Nos Elísios estão os que tenham sido fiéis ao amor (v. 65); no setor dos criminosos (scelerata...sedes, v. 67), entre outros infelizes, os que violaram as regras do amor, ou, mais especificamente, os amores do nar-

67 Em 1.2, a deusa também é evocada como estímulo à confiança (fortes adiunat ìsa Venus, 1.2.16).

68 Como tener, o adjetivo tenuis guarda carga metapoética, associada à matéria e elocução mais simples. É como "tênue", lembremos, que Melibeu caracteriza a flauta de Títiro, bem no início da primeira Bucólica de Virgílio (tenui...auena, v. 2). E esse não é o único diálogo entre as obras de Tibulo e Virgílio. Nesta elegia, a descrição da Idade de Ouro feita por Tibulo tem muitos paralelos com aquela que Virgílio realiza na quarta Bucólica. Cf. VEYNE (1985, pp. 40-44). 
rador (quicumque meos niolanit amores ${ }^{69}$, v. 81). A referência é bastante pessoal. O eu poético deseja punição para aqueles que tenham violado seus amores (com todos os sentidos que a expressão pode assumir) ou the desejado prolongadas campanhas (lentas...militias, v. 82). Campanhas militares, imaginaríamos, pois que as vê com maus olhos; mas talvez também amorosas (coerentemente com o tópos elegíaco da militia amoris), e mal vistas porque fracassadas. Tanto que, a seguir, possivelmente inseguro quanto à constância da amada, o narrador lhe roga que permaneça casta (at tu casta precor maneas, v. 83). Certa leveza no pedido pode ser notada se o leitor acaso se lembrar, segundo sugere MALTBY (p. 83-84), de cenas de comédia nova, gênero presente em diversos momentos da elegia romana (BEM, 2011).

Contudo, notamos uma referência mais diretamente elegíaca ao recordarmos o pedido feito em 1.2, quando o eu poético, incitando Délia a despistar os guardas, faz a ressalva de que não se valha dos ardis para encontrar-se com outros. A guarda (custos, v. 84), que em 1.2 era obstáculo ao encontro dos amantes, aqui na elegia 1.3 se torna uma aliada do narrador, pois que, distante de Délia, precisa de alguém que olhe por ela e lhe resguarde o pudor. E é na companhia dessa guarda, uma senhora diligente (sedula...anus, v. 84), que o eu poético passa a imaginar a amada a tecer, como Penélope, entretida na Odisseia em serões até se entregar ao sono (1.3.89-92):

tunc ueniam subito nec quisquam nuntiet ante sed uidear caelo missus adesse tibi.

Tunc mihi qualis eris, longos turbata capillos, obuia nudato, Delia, curre pede.

Então virei de pronto, anúncio não se faça, do céu tão-só me vejam vindo a ti. Então - não importa se desfeita a cabeleira a mim, com pés desnudos, Délia, corre.

Em sonho, o encontro enfim acontece. O movimento final da elegia 1.3 inverte, em certa medida, o que acontece em 1.2. No poema anterior, muito em-

69 Sobre a configuração do mundo dos mortos em Tibulo e sua relação com o poema de Lucrécio, cf. LEE-STECUM (pp. 123-126). Entre outras coisas, o estudioso afirma: “[...] the poet/lover's heaven and hell are described in terms of amor and its associated power relations as he has experienced them, and as he would ideally reconstruct them. In this respect, they can easily be assimilated to the critique of these myths that Lucretius puts forward. Just as Lucretius claims, the poet constructs his Hell (and his Elysium) in the image of what he has experienced during life" (p. 225). 
bora se encontrassem próximos um do outro, os amantes jamais chegavam a se encontrar, pois que impedidos por uma porta e seus guardas. Aqui, por muito distantes que estejam, o encontro, mesmo que onírico, se consuma; como se Délia, ausente em sua presença em 1.2, agora se fizesse presente pela ausência reluzente (vv. 93-94):

[...] hunc illum nobis Aurora nitentem

Luciferum roseis candida portet equis

[...] traga-nos a Aurora, cândida, o amanhecer com seus cavalos róseos.

Portanto, segundo esses versos podemos pensar que, assim como Délia, a elegia 1.3 se apresenta por meio da recusa, incorporando exageradamente a elocução de um mundo épico: tanto na descida onírica ao Inferno virgiliano como no início e fim homéricos. Ambas são instâncias em que se indica que, para privilegiar o amor elegíaco, o eu poético imita os percursos de Odisseu pela Feácia, e evoca a reluzente "roseodátila aurora".

\section{Referências}

BEM, L. A. de. Metapoesia e Confluência Genérica nos Amores de Ovídio. Tese de Doutoramento em Letras Clássicas, orientada por Paulo Sérgio de Vasconcellos. Campinas: Instituto de Estudos da Linguagem, Universidade Estadual de Campinas, 2011, inédita.

CAIRNS, F. Generic Composition in Greek and Roman Poetry. Ann Arbor: Michigan Classical Press, 2010.

CARDOSO, I. T. Estico de Plauto. Campinas: Editora da Unicamp, 2006.

CARDOSO, Z. de A. "Elementos Religiosos nas Elegias de Tibulo". In: Calíope: Presença Clássica. vol. 12, n. 1, 2004. pp. 93-111.

CART, A. et al. Gramática Latina, tradução Maria Evangelina Villa Nova Soeiro. São Paulo: T. A. Queiroz: Editora da Universidade de São Paulo, 1986.

DAVIS, G. Polyhymnia: the Rethoric of Horatian Lyric Discourse. Berkeley: University of California Press, 1991.

DINTER, M. "Epic and Epigram: Minor Heroes in Vergil's Aeneid". In: Classical Quarterly, 55, 2005. pp. 153-169.

FRAUSTADT. Tibulls Elegien: Lateinisch und Deutsch von Werner Fraustadt. München: Ernst Heimeran Verlag, 1940. 
KOENEN, L. "Egyptian Influence in Tibullus". In: Illinois Classical Studies. vol. 1, 1976. pp. 127-159.

LEE-STECUM, P. Powerplay in Tibullus: Reading Elegies Book One. Cambridge: Cambridge University Press, 1998.

MACRIS. Tibulle. Élégies, présentation et traduction du latin par Pierre Macris. Paris: Orphée / La Différence. 1992.

MALTBY. Tibullus. Elegies, text, introduction and commentary by Robert Maltby. Cambridge: Francis Cairns Publications, 2002.

MOSELLA. Tibullo. I Carmi, con appendice pseudotibulliana: testo; versione e note di Giuseppe Galati Mosella. $2^{2}$ ed. Bologna: L. Cappelli, 1938.

PICHON, R. Index Verborum Amatoriorum. Hildesheim / Zürich / New York: Georg Olms Verlag, 1991.

PONCHON. Tibulle et les Auteurs du Corpus Tibullianum, texte établi et traduit par Max Ponchont. Paris: Les Belles-Lettres, 1955.

PUTNAM, M. C. J. Tibullus: a Commentary. Norman: University Oklahoma Press, 1973.

VEYNE, Paul. A Elegia Erótica Romana: o Amor, a Poesia e o Ocidente, tradução Milton Meira do Nascimento e Maria das Graças de Souza Nascimento. São Paulo: Brasiliense, 1985. 